\title{
METHICILLIN-RESISTANT STAPHYLOCOCCUS AUREAS: AN INTERVENTIONAL STUDY AMONG HEALTH CARE WORKERS OF SURGICAL ICU AT ZAGAZIG UNIVERSITY HOSPITAL, EGYPT
}

\author{
By \\ ${ }^{1}$ Abdelsalam NM, ${ }^{1}$ Bakry HM, ${ }^{2}$ Bolbol SA, ${ }^{1}$ Abdelsalam AE and ${ }^{3}$ Atef DM \\ ${ }^{1}$ Department of Public Health and Preventive medicine, ${ }^{2}$ Department of Community, Environmental and \\ Occupational Medicine, ${ }^{3}$ Department of Clinical Pathology, \\ Faculty of Medicine, Zagazig University, Egypt.
}

\begin{abstract}
Introduction: Methicillin-Resistant Staphylococcus Aureas (MRSA) is largely a hospital-acquired infection that is capable of causing severe infections. Comprehensive MRSA control programs, have reported success in controlling transmission and reduced acquisition of MRSA in high-risk units in hospitals. Aim of work: To measure the current prevalence of MRSA colonization and measure the effect of health education program on knowledge and attitude about MRSA infection and control among health care workers. Materials and methods: An intervention study was conducted over 8 months upon 54 working staff in the Surgical ICU at Zagazig university hospital and 144 isolates were taken from the health care workers, patients and the environment. Results: Out of 144 isolates, 36 were positive for MRSA with a rate of $61 \%$ was on the side of the health care workers. Our findings revealed significant improvement in the knowledge and attitude after application of the educational program in health care workers. Conclusion: Further targeted health education programs for health care workers are needed to increase their awareness and understanding of the microorganism and the importance of the adherence to the infection control guidelines to break the chain of transmission in the health care setting.
\end{abstract}

Key words: Attitude, Infection control, Knowledge, MRSA and Health education. 


\section{Introduction}

Methicillin-ResistantStaphylococcus Aureas (MRSA) is a serious strain of Staphylococcus Aureas that causes lifethreatening pneumonia, bloodstream infections and surgical site infections in medical facilities (CDC, 2015).

MRSA infections are known to be associated with significant morbidity, increased length of hospital stays, higher cost of treatment and high mortality (Shibabaw et al., 2013).

ICUs are particularly appropriate for the rapid emergence and spread of MRSA. Patients in the ICU have special risk factors make them extremely vulnerable to healthcare associated MRSA (Radhakrishna et al., 2013).

Prevention efforts in a variety of healthcare settings have been shown to significantly decrease healthcare associated MRSA. However, the frequency of hand hygiene and the consistent use of contact precautions are often found to be inadequate or improperly implemented (Yamakawa et al., 2011).

Healthcare workers (HCWs) may be at a higher risk for chronic colonization with resistant bacteria than the general population (Clock et al., 2010) with nasal carriage rates ranged between $6 \%$ to $17.8 \%$ (Huskins et al., 2011). Also HCWs have been implicated as a reservoir for transmission of resistant organisms like MRSA to patients in a number of published outbreak reports (Siegel et al., 2007).

HCWs have an essential role in the prevention of MRSA transmission in different health care settings. The knowledge gained and perceived by HCWs about MRSA has a tremendous effect on their attitude to continuously take preventive measures towards decreasing healthcare associated MRSA (Seibert et al., 2014).

\section{Aim of Work}

The goal of our study was to measure the current prevalence of MRSA colonization and to assess the effect of health education program on the knowledge and attitude of health care workers in surgical intensive care unit at Zagazig university hospital about MRSA infection and control.

\section{Materials and methods}

- Study design: An interventional field trial. 
- Place and duration of study: In the Surgical ICU at Zagazig University Hospitals during the period of 8 months (from February 2014 till September 2014) through three phases:

- Study sample: Out of 7 ICUs in Zagazig University hospitals, surgical ICU was selected by simple random sample and taken as a cluster. All working medical and paramedical personnel participated in the study (14 doctors, 30 nurses and 10 support staff).

\section{- Study methods:}

1-Assessment phase: This phase was conducted over a period of 3 months to:

- Measure MRSA colonization prevalence among the working staff, in the surrounding environment and patients who were admitted during the period of specimens' collection.

- Assess the knowledge and attitude of the working medical staff about MRSA and MRSA infection control guidelines.

- Assess the adherence of the working medical staff to infection control guidelines.
2-Implementation phase: was conducted over 3 months through educational intervention sessions for dissemination of information about MRSA and the standard infection control guidelines.

3-Evaluation phase: was conducted over 2 months to reassess the knowledge and attitude of the medical staff about MRSA infection and control.

\section{4- Data collection tools:}

- A structured questionnaire to assess the knowledge of the participants about MRSA.

- A structured questionnaire to assess the attitude of the participants regarding adherence to infection control guidelines that cover different aspects of the health belief model.

- Achecklist to assess the performance of the working staff guided by Standard Infection Control Precautions (Malone, 2005).

\section{5-Experimental tools:}

Colored brochures and power point presentations about MRSA, its mode 
of transmission, the importance of its control and how to adhere to infection control guidelines were used in the health education sessions to improve the awareness and attitude of the working staff.

\section{Laboratory investigations:}

Laboratory investigations were carried out at The Clinical Pathology Department, Zagazig University Hospitals. 144 clinical Specimens were taken from the environment and from all working staff in the ICU with a response rate $98.1 \%$ as well as patients admitted to the ICU at the time of specimens collection. Specimens taken from personnel were in the form of nasal swabs taken from both nostrils and those from the environment were environmental swabs. Swabs taken from the environment were 10 and those from personnel were 84 from doctors and nurses, 20 from support staff and 30 from patients.

\section{Specimens Culture:}

Firstly, swabs were grown in nonselective blood agar incubation at $37^{\circ} \mathrm{C}$. Staph. aureus was identified by coagulase test (oxoidLTd; UK),
chromID MRSA SMART Agar and vitek 2 (Biomerieux).

\section{1. chromID MRSA SMART} Agar (bioMérieux, Marcy l'Etoile, France): consists of a chromogenic substrate and a combination of several antibiotics, which favor the growth of MRSA (Kumar et al., 2014). The growth of any pink or mauve coloration was considered to be positive MRSA. The procedure was performed as recommended by the manufacturer.

\subsection{Vitek ${ }^{\circledR 2}$ automated system}

(Biomerieux): the Vitek 2 cards (PN- ID cards) were inoculated following the instructions of the manufacturer (Ling et al., 2003). Every $15 \mathrm{~min}$, Fluorescence was measured, and the results of identification were determined after $3 \mathrm{hrs}$.

\section{Antimicrobial susceptibility testing:}

The minimum inhibitory concentrations (MICs) obtained by both methods, VITEK- 2 system compared with those obtained by the reference method. 
2.1. Disc diffusion method for detection of MRSA: According to NCCLS guidelines, the well isolated colonies of S. aureus were tested by disk diffusion (as the reference method) (National Committee for Clinical Laboratory Standards, 2009). The inhibition zone diameter $>19 \mathrm{~mm}$ around cefoxitin disk or $>10 \mathrm{~mm}$ around oxacillin disk after incubation $18-19 \mathrm{~h}$ at $35^{\circ} \mathrm{C}$ were oxacillin resistant and PBP2 a positive (MRSA) (Hawkey, 2009).

\subsection{Vitek®2 automated system} (Biomerieux): Use AST-GP67 card (Ref. no. 22226) (Biomerieux) for vitek2 system. Vitek2 system interpret any $\mathrm{S}$. aureus isolate that tested positive by cefoxitin screen (MIC $>6 \mu \mathrm{g} / \mathrm{ml})$ as oxacillin resistant.

\section{Consent}

An informed verbal consent was obtained from physicians, nurses, support staff and patients and they were reassured about the confidentiality of any obtained information and that the results would be used for the purpose of research.

\section{Ethical approval}

Before carrying out the study, Institutional Review Board (IRB) of the faculty of Medicine, Zagazig University approved the study protocol. The necessary official permission was taken from the head of Anesthesia department and the head of Surgical ICU.

\section{Data management}

After data collection, data were coded, entered and analyzed using SPSS (Statistical Package for Social Science) version 19. Mcnemar test was used for comparing descriptive data and paired t test was used for comparing means. $\mathrm{P}$ value $(\leq 0.05)$ was considered significant difference and $\mathrm{P}$ value $(\leq$ $0.01)$ was considered highly significant difference. 


\section{Results}

Table 1: Nurses and physicians infection control practice.

\begin{tabular}{|c|c|c|c|c|}
\hline \multirow{2}{*}{ Questions } & \multicolumn{2}{|c|}{ Physicians (\%) } & \multicolumn{2}{|c|}{ Nurses (\%) } \\
\hline & Done & Not done & Done & Not done \\
\hline keep nails short, clean and polish free & 85.7 & 14.3 & 90 & 10 \\
\hline $\begin{array}{l}\text { Avoid wearing jewelry, especially rings } \\
\text { with ridges or stones. }\end{array}$ & 71.4 & 28.6 & 26.7 & 73.3 \\
\hline $\begin{array}{l}\text { Maintain hand hygiene: } \\
\text { Before and after each patient contact } \\
\text { After handling blood and body fluids } \\
\text { and items contaminated with blood } \\
\text { and body fluids } \\
\text { Prior to aseptic technique } \\
\text { After removing protective clothing/ } \\
\text { gloves } \\
\text { Before handling invasive devices } \\
\text { Following bed making } \\
\text { Proper drying of hands }\end{array}$ & $\begin{array}{c}7.1 \\
7.1 \\
\\
7.1 \\
7.1 \\
0 \\
\text { NA } \\
0\end{array}$ & $\begin{array}{c}92.9 \\
92.9 \\
92.9 \\
92.9 \\
100 \\
\text { NA } \\
100\end{array}$ & $\begin{array}{c}100 \\
100 \\
100 \\
46.7 \\
100 \\
100 \\
0\end{array}$ & $\begin{array}{c}0 \\
0 \\
\\
0 \\
53.3 \\
0 \\
0 \\
100\end{array}$ \\
\hline $\begin{array}{l}\text { Maintain cleanliness of: } \\
\text { General environment } \\
\text { Patient-related equipment }\end{array}$ & $\begin{array}{l}100 \\
100\end{array}$ & $\begin{array}{l}0 \\
0\end{array}$ & $\begin{array}{l}100 \\
100\end{array}$ & $\begin{array}{l}0 \\
0\end{array}$ \\
\hline $\begin{array}{l}\text { Use disposable gloves when handling } \\
\text { blood and body fluids. }\end{array}$ & 0 & 100 & 100 & 0 \\
\hline $\begin{array}{l}\text { Use disposable aprons for direct patient } \\
\text { care, bed making and aseptic techniques. }\end{array}$ & 0 & 100 & 0 & 100 \\
\hline Dispose of waste safely. & 100 & 0 & 100 & 0 \\
\hline Avoid overcrowding patients. & 100 & 0 & 100 & 0 \\
\hline $\begin{array}{l}\text { Avoid unnecessary patient transfers } \\
\text { between wards. }\end{array}$ & 100 & 0 & 100 & 0 \\
\hline $\begin{array}{l}\text { Isolate patients with a known or } \\
\text { suspected infection. }\end{array}$ & 0 & 100 & 0 & 100 \\
\hline
\end{tabular}

NA: Not Applicable

Table 1 shows that on assessing both physicians and nurses infection control practice we found that only (26.7\%) of nurses avoid wearing jewelry while working. Maintaining hand hygiene was not done by the majority of physicians $(92.9 \%)$. 
Table 2: Identification of 144 isolates by ChromID MRSA SMART agar after $24 \mathrm{~h}$ of incubation.

\begin{tabular}{|l|c|c|c|}
\hline & $\begin{array}{c}\text { Number of } \\
\text { isolates }\end{array}$ & $\begin{array}{c}\text { ChromID MRSA } \\
\text { Positive N (\%) }\end{array}$ & $\begin{array}{c}\text { ChromID MRSA } \\
\text { Negative N (\%) }\end{array}$ \\
\hline Doctor \& Nurse nasal swabs & 89 & $22(24.7)$ & $67(75.3)$ \\
\hline Support staff nasal swabs & 10 & $0(0.0)$ & $10(100.0)$ \\
\hline Patient nasal swabs & 30 & $12(40.0)$ & $13(80.0)$ \\
\hline Environmental swabs & 15 & $2(13.3 \%)$ & $108(75 \%)$ \\
\hline Total (\%) & 144 & $36(25 \%)$ & $13)$ \\
\hline
\end{tabular}

Table (2) shows that out of 144 isolates by chromID MRSA SMART agar after $24 \mathrm{~h}$ of incubation, $25 \%$ of the swabs were positive. 
Table 3: knowledge of health-care workers on (MSRA) infection in surgical ICU before and after intervention.

\begin{tabular}{|c|c|c|c|}
\hline Knowledge about MRSA infection & Pretest $(\%)$ & Posttest (\%) & P value \\
\hline $\begin{array}{l}\text { Definition of MRSA:* } \\
\text { Correct (nurses) } \\
\text { Correct (physician) }\end{array}$ & $\begin{array}{c}6.6 \\
64.2\end{array}$ & $\begin{array}{l}33.3 \\
85.7\end{array}$ & $\begin{array}{l}<0.05 \\
>0.05\end{array}$ \\
\hline $\begin{array}{l}\text { Mode of transmission of MRSA:* } \\
\text { Correct (nurses) } \\
\text { Correct(physician) }\end{array}$ & $\begin{array}{l}20.0 \\
71.4 \\
\end{array}$ & $\begin{array}{l}53.3 \\
92.8 \\
\end{array}$ & $\begin{array}{l}<0.01 \\
>0.05\end{array}$ \\
\hline $\begin{array}{l}\text { Source of infection of MRSA:* } \\
\text { Correct(nurses) } \\
\text { Correct(physician) }\end{array}$ & $\begin{array}{l}53.3 \\
78.5 \\
\end{array}$ & $\begin{array}{l}63.3 \\
92.8 \\
\end{array}$ & $\begin{array}{l}>0.05 \\
>0.05\end{array}$ \\
\hline $\begin{array}{l}\text { High risk group for MRSA:* } \\
\text { Correct (nurses) } \\
\text { Correct (physician) }\end{array}$ & $\begin{array}{l}30.0 \\
71.4 \\
\end{array}$ & $\begin{array}{l}66.7 \\
85.7 \\
\end{array}$ & $\begin{array}{l}<0.05 \\
>0.05 \\
\end{array}$ \\
\hline $\begin{array}{l}\text { Aim of prevention of Nosocomial infection:* } \\
\text { Correct (nurses) } \\
\text { Correct(physician) }\end{array}$ & $\begin{array}{c}76.7 \\
100.0\end{array}$ & $\begin{array}{c}93.3 \\
100.0\end{array}$ & $\begin{array}{c}<0.05 \\
-\end{array}$ \\
\hline $\begin{array}{l}\text { Guidelines on (MRSA) prevention and } \\
\text { control:* } \\
\text { Correct (nurses) } \\
\text { Correct(physician) }\end{array}$ & $\begin{array}{l}40.0 \\
71.4\end{array}$ & $\begin{array}{l}66.7 \\
92.8\end{array}$ & $\begin{array}{l}<0.05 \\
>0.05\end{array}$ \\
\hline $\begin{array}{l}\text { What measures are taken when an } \\
\text { unexpected MRSA is discovered :* } \\
\text { Correct (nurses) } \\
\text { Correct (physicians) }\end{array}$ & $\begin{array}{l}10.0 \\
28.5\end{array}$ & $\begin{array}{l}50.0 \\
85.7\end{array}$ & $\begin{array}{l}<0.01 \\
<0.01\end{array}$ \\
\hline $\begin{array}{l}\text { Total knowledge: } * * \\
\mathrm{X} \pm \mathrm{SD} \text { (nurses) } \\
\mathrm{X} \pm \mathrm{SD} \text { (physician) }\end{array}$ & $\begin{array}{c}4.8 \pm 1.5 \\
10.4 \pm 1.8\end{array}$ & $\begin{array}{c}9.1 \pm 1.3 \\
12.7 \pm 1.5\end{array}$ & $\begin{array}{l}<0.01 \\
<0.01\end{array}$ \\
\hline
\end{tabular}

*Mcnemar test

**Paired t-test

Table (3) shows that total knowledge score was significantly increased in both groups as in nurses $(4.8 \pm 1.5$ increased to $9.1 \pm 1.3)$ and in physicians $(10.4 \pm 1.8$ increased to $12.7 \pm 1.5)$ after intervention. 
Table 4: Attitude of health-care workers on (MSRA) infection control in surgical ICU before and after intervention

\begin{tabular}{|c|c|c|c|c|c|c|}
\hline \multirow{2}{*}{$\begin{array}{l}\text { Perception of MRSA infection } \\
\text { control }\end{array}$} & \multicolumn{2}{|c|}{ Physicians (\%) } & \multirow[t]{2}{*}{ P value } & \multirow{2}{*}{$\begin{array}{c}\begin{array}{c}\text { Nurses } \\
(\%)\end{array} \\
\text { pretest }\end{array}$} & \multicolumn{2}{|c|}{ P-value } \\
\hline & pretest & $\begin{array}{c}\text { Post- } \\
\text { test }\end{array}$ & & & $\begin{array}{c}\text { Post- } \\
\text { test }\end{array}$ & \\
\hline $\begin{array}{l}\text { Severity: } \\
\text { MRSA is national problem } \\
\text { MRSA is a problem in this hospital }\end{array}$ & $\begin{array}{l}71.4 \\
85.7\end{array}$ & $\begin{array}{l}78.5 \\
92.8\end{array}$ & $\begin{array}{l}>0.05 \\
>0.05\end{array}$ & $\begin{array}{l}33.3 \\
26.7 \\
\end{array}$ & $\begin{array}{l}63.3 \\
73.3 \\
\end{array}$ & $\begin{array}{l}<0.01 * \\
<0.01 *\end{array}$ \\
\hline $\begin{array}{l}\text { Susceptibility: } \\
\text { I'm concerned that I will transmit } \\
\text { MRSA to my family at home }\end{array}$ & 50.0 & 92.8 & $<0.01 *$ & 20.0 & 80.0 & $<0.01 *$ \\
\hline $\begin{array}{l}\text { Benefit: } \\
\text { If I clean my hands and wear gowns } \\
\text { and gloves as recommended I will } \\
\text { decrease my risk of getting MRSA. } \\
\text { If I clean my hands and wear gowns } \\
\text { and gloves as recommended I will } \\
\text { decrease my patient risk of getting } \\
\text { MRSA. }\end{array}$ & 85.7 & 92.8 & $\begin{array}{l}>0.05 \\
>0.05\end{array}$ & 50.0 & 76.6 & $\begin{array}{l}<0.01 * \\
<0.01 *\end{array}$ \\
\hline $\begin{array}{l}\text { Self-efficacy: } \\
\text { When staff on this unit don't wear } \\
\text { gown, gloves before touching } \\
\text { a patient with MRSA ,I feel } \\
\text { comfortable reminding them. } \\
\text { When staff on this unit don't wash } \\
\text { their hands before touching a patient } \\
\text { with MRSA, I feel comfortable } \\
\text { reminding them. }\end{array}$ & 42.8 & 71.4 & $>0.05$ & 30.0 & 60.0 & $<0.01 *$ \\
\hline $\begin{array}{l}\text { Cues to action: } \\
\text { I have meaningful education } \\
\text { about MRSA } \\
\text { I know someone have MRSA }\end{array}$ & $\begin{array}{l}50.0 \\
21.4\end{array}$ & $\begin{array}{l}92.8 \\
35.7\end{array}$ & $\begin{array}{l}<0.01 * \\
>0.05\end{array}$ & $\begin{array}{c}23.0 \\
3.3\end{array}$ & $\begin{array}{l}83.3 \\
16.6\end{array}$ & $\begin{array}{r}<0.01 * \\
>0.05\end{array}$ \\
\hline
\end{tabular}

*Mcnemar test, P-value $<0.01$ Significant

Table 4 shows that there were significant improvement in the attitude of nurses towards all items MRSA infection control after intervention. Physicians only showed significant improvement in the attitude after intervention regarding the concern of transmitting MRSA to families at home (50.0\% increased to $92.8 \%$ ) and towards cues of action to MRSA by having a meaningful education about MRSA (50.0\% increased to $92.8 \%$ ). 


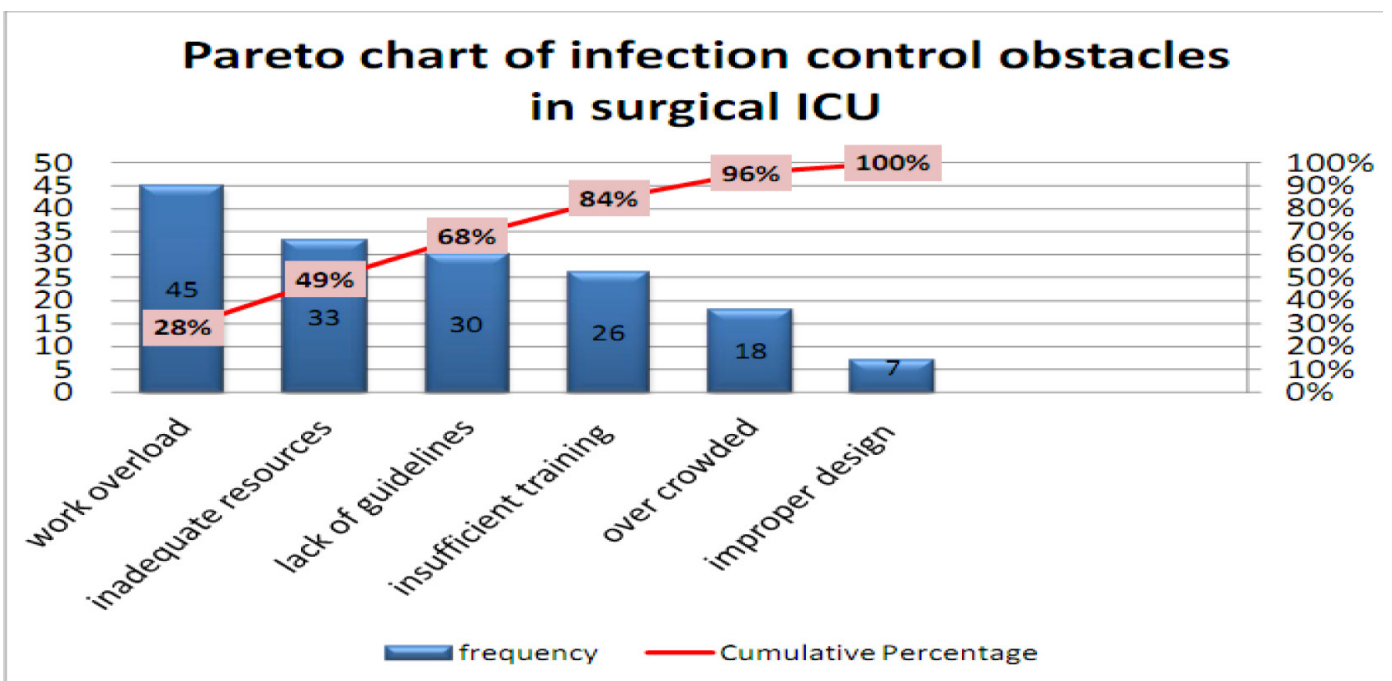

Figure 1: Pareto chart for identifying the infection control obstacles in surgical ICU.

Asking the participants about their opinion on the most common obstacles that hinder the infection control practice in the surgical ICU unit, Pareto chart showed that the most frequent (Vital Few) obstacles were work overload, inadequate resources and lack of guidelines.

\section{Discussion}

Methicillin-resistant S. aureus (MRSA) is one of the most commonly reported gram-positive multi drug resistant pathogens in the ICU. MRSA causes community and healthcareassociated infections, approximately $20 \%$ of the healthy subjects persistently have nasal colonization with S. aureus (Antimicrobial resistance surveillance in Europe, 2012). Emergence of resistant pathogens generates a global wave spreading between continents. Consequently, antibiotic resistance is a worldwide problem requiring coordinated international surveillance and infection control measures (Spellberg and Gilbert, 2014).

This study was implemented in surgical ICU of Zagazig University Hospitals toidentify the point prevalence of MRSA, and assessing level of 
knowledge and attitude among health care providers about MRSA before and after implementing an organized health education program.

The study participants included 14 physicians, 30 nurses and 10 supporting staff. The age of more than half of physicians and nurses lied between 2030 years however most of the supporting staff were more than 30 years. $(42.8 \%)$ of physicians had less than 5 years duration of experience, most of nurses had more than 10 years of experience compared to 5-10 years for supporting staff. The majority of physicians and all workers work for more than 40 hours per week but most of the nurses work from 20-40 hours. Most of the sample participants work for other institutions. In addition the majority had training courses in infection control.

Infection control infrastructure was assessed at the beginning of the study and we observed that most of basic infrastructures (antiseptic, protective clothes and sterilizers) were always available. However the only noticed defect was in posters available for infection control guidelines related to central venous catheter, urinary catheter and ventilator.
The study showed relatively high prevalence of MRSA colonization among medical staff (Table 2) which was in contrary to other study conducted in India reported comfortably low $(2.5 \%)$ MRSA carriage among healthcare workers who were involved in the management of critically ill patients (Radhakrishna et al., 2013). Also other study reported high prevalence of colonization (19\%) among their medical staff (Bisaga et al., 2008). On the other hand we found prevalence of $13 \%$ positive MRSA environmental swabs which was in accordance with another study conducted in a community hospital in Canada reported the identification of MRSA (12\%) from a variety of surfaces in the general hospital environment (Faires et al., 2012).

Physicians and nurses practice of infection control measures was clarified in (Table 1). Most of the staff follows infection control measures, however physicians were better in avoiding wearing jewelry, in contrast most of nurses follow hand hygiene rules more than physicians. These results may be explained that the nurses deal directly with the patients more than physicians 
and they achieve most of the dirty work, or may be due to the majority of nurses attained infection control courses, and they had longer years of experience. Paudyal et al., 2008 found that only $0.3 \%$ of the respondents achieved maximum scores for infection control practice items. Overall hand-hygiene compliance obtained from observational study done by Patarakul et al., 2005 was less than $50 \%$. Additionally Stein et al 2003 noted that doctors are less adherent to different infection control guidelines than nurses. Gedic et al., 2013 reported many for the lack of adherence with recommendations to hand hygiene including skin irritation, inaccessible supplies, interference with worker-patient relation, patient needs perceived as priority, wearing gloves, forgetfulness, ignorance of guidelines, insufficient time, high workload and understaffing, and lack of scientific information demonstrating impact of improved hand hygiene on hospital infection rates.

On asking the participants about their opinion on the most common obstacles that hinder the infection control practice in the surgical ICU unit (Figure 1) the main obstacles were found to be work overload, inadequate resources and lack of infection control guidelines application. These obstacles can be solved by focusing on increasing infection control budget; intense training for health care providers and adapting standard infection control guidelines will solve $80 \%$ of the problem. This was in agreement with Madani et al., ,2009 who stated that the general barriers to optimal infection control practices in low-income and middle-income countries are lack of financial support, inadequate numbers of trained personnel working in infection control, understaffed hospital units, and insufficient equipment and supplies.

Work overload as the main obstacle may be explained by low number of staff in comparison to high level of turnover in ICU. In addition most of them work for other institutions. Consistently Alpe et al, 2011 ordered the main barriers of infection control in ICU in the following order, low compliance of hand hygiene, excessive number of patients and workload, inadequate staff and personal protective equipment. In 
the same context Pascale and Gurses, 2008 found work overload of nurses (due to shortage in their number) as the main cause of not following infection control principles.

Table 3 clarified the difference in the level of knowledge as regards MRSA before and after health education program. There was significant improvement in the total level of knowledge of both physicians and nurses after implementing the program. Significant improvement of nurses' knowledge about definition, modes of transmission, high risk groups and guidelines on (MRSA) prevention and control and measures that taken when an unexpected MRSA was noticed after the program. In consistence with these results a study conducted by Easton et al., 2007 who found that knowledge on many aspects of MRSA and especially its management was deficient among health care providers. In another study done by Kheder, 2012, he found that nurses were more likely to display negative knowledge about MRSA.

Similar study carried out by Adriana et al., 2010 found that more than $(43.7 \%)$ of nurses didn't know the basis of MRSA. Soliman et al., 2013 concluded no significant difference between nurses and physicians in their awareness of MRSA routes of transmission, but significantly more nurses were aware of the main risk factors. In a study done by Sadaka, 2009 , only $20.3 \%$ of physicians and $23.4 \%$ of nurses correctly identified the most important risk factor for infection. Additionally in a study performed by Silva et al., 2010, they found limited level of knowledge in all aspects of MRSA especially as regards factors related to the nursing teams' adherence to preventive measures.

Positive attitude of health-care workers towards MSRA infection control before and after intervention was listed in (Table 4). As regards physicians most of them had positive attitude with no significant change after program except for the points of concern about transmitting MRSA to family at home, and having meaningful education about MRSA. In comparison there is significant improvement of the positive attitude of nurses about MRSA after the program. Consistently Navarro-San Francisco et 
al., 2013 found that physicians mostly considered that antimicrobial resistance was a significant problem at national level $(94.3 \%)$, at their institution $(91.3 \%)$, and for their daily practice $(83.8 \%)$, additionally they considered their training regarding antibiotics insufficient.

In a study done by Seibert et al., 2014 they noted that less than half of health care workers believed that MRSA was a problem in their workplace or worried about bringing MRSA from the hospital to home, also most of them had the perception that they are not at risk because they believe that MRSA organisms die quickly in the environment. Previous study done by Koltes, 2009 had found that health care workers who believe that MRSA cause severe illness engage in better preventive behaviors.

Health care provider education is a fundamental step for MRSA prevention and control. To change behavior we are in need for sufficient knowledge and sound attitude. Balbale et al., 2015 demonstrated that to ensure proper implementation of MRSA infection prevention and control guidelines, we are in need for guideline dissemination in all settings, frequent and systematic provider education, strong support from leaders and addressing barriers to fulfill guidelines and recommendations.

\section{Conclusion and recommendations}

MRSA colonization prevalence among healthcare workers was relatively high, so more attention should be given to the prevention of it. Our program succeeded in improving the knowledge and attitude of the health care workers regarding MRSA infection and control. Assessment of adherence of the heath care workers to infection control guidelines is recommended. Also further targeted health education programs for health care workers to increase their awareness and understanding of the microorganism are recommended.

\section{Conflict of interest}

The authors declare that there are no conflict of interests. This research paper was financed totally by the authors of the study.

\section{Limitations}

We didn't assess the practice of the health care workers after the intervention as it takes very long time to track all members. 


\section{Acknowledgements}

\section{The authors appreciate the support} of the Anesthesia department and Surgical ICU staff members throughout the work.

\section{References}

1. Alpe E, Leblebicioglu H, Doganay $M$ and Voss A (2011): Infection control practice in countries with limited resources. Annals of clinical microbiology and antimicrobials; 10(1):1. Available at: https://annclinmicrob.biomedcentral.com/ articles/10.1186/1476-0711-10-36

2. Antimicrobial resistance surveillance in Europe (2012): Annual report of the European Antimicrobial Resistance Surveillance Network (EARS-Net). Stockholm. Available at: http:// ecdc.europa.eu/en/publications/Publications/ antimicrobial-resistance-surveillanceeurope-2012.pdf

3. Balbale S, Hill J, Guihan M, Hogan T, Cameron K, Goldstein B and Evan C (2015): Evaluating implementation of methicillinresistant Staphylococcus aureus (MRSA) prevention guidelines in spinal cord injury centers using the PARIHS framework: a mixed methods study. Implement Sci.; 10:130. Available at https://www.ncbi.nlm.nih.gov/ pubmed/26353798

4. Bisaga A, Paquette K, Sabatini L and Lovell EO (2008): A prevalence study of methicillinresistant Staphylococcus aureus colonization in emergency department health care workers. Ann Emerg Med; 52(5):525.

5. Centers for Disease Control and Prevention (CDC) (2015): Methicillin-resistant Staphylococcus aureus (MRSA) infections. CDC. Available at: http://www.cdc.gov/mrsa/

6. Clock S, Cohen B, Behta M, Ross B and Larson E (2010): Contact precautions for multidrugresistant organisms: Current recommendations and actual practice. AJIC; 38 (2): 105-111. Available at: http://www.ajicjournal.org/article/ S0196-6553 (09)00837-2/abstract.

7. Easton PM, Sarma A, Williams FL, Marwick CA, Phillips G and Nathwani D (2007): Infection control and management of MRSA: assessing the knowledge of staff in an acute hospital setting. J Hosp Infect; 66(1):29-33.

8. Faires M, Pearl D, Ciccotelli W, Straus K, Zinken G, Berke O and Wees JS (2012): A prospective study to examine the epidemiology of methicillin-resistant Staphylococcus aureus and Clostridium difficile contamination in the general environment of three community hospitals in southern Ontario, Canada. BMC Infect Dis; 12:290.

9. Gedik H, Voss TA and Voss A (2013): Patient's Safety in Your Hands. Mediterr J Infect Microb Antimicrob; 2:8 Available at:https:// www.researchgate.net/profile/Habip_Gedik2/ publication/261362177_Patient\%27s_ Safety_in_Your_Hands-_Hastalari_Ellerinle_ Koru/links/00b495340203a09bce000000. pdf?origin=publication_detail

10. Hawkey PM (2009): Low-level glycopeptide resistance in methicillin resistant Staphylococcus aureus and how to test. Clin Microbiol Infect; 15: 2-9.

11. Huskins W, Huckabee C, O'Grady N, Murray P, Kopetskie H, Zimmer L, et al. (2011): Intervention to Reduce Transmission of Resistant Bacteria in Intensive Care. N Engl J Med; 364:1407-1418. Available at: http://www. nejm.org/doi/full/10.1056/NEJMoa1000373.

12. Kheder K (2012): A survey among Medical Staff about the Knowledge and Perception of Methicillin-resistant Staphylococcus aureus in Khartoum state 2012. JPBMS; 22(22):14.

13. Koltes LA (2009): Healthcare workers' attitudes, understanding and perceived risk of methicillin-resistant Staphylococcus aureus [dissertation]. Fargo (ND): North Dakota State University.

14. Kumar VA, Steffy K, Chatterjee M, Sugumar M, Dinesh KR, Manoharan A, et al. (2014): Detection of oxacillin-susceptible mecA- 
positive Staphylococcus aureus isolates by use of chromogenic medium MRSA ID. J clin microbiol; 51:318-319.

15. Ling W, Liu K and Cheng B (2003): Evaluation of the VITEK 2 System for Rapid Direct Identification and Susceptibility Testing of Gram-Negative Bacilli from Positive Blood Cultures. J clin microbiol; 41(10):4705-4707.

16. Madani N, Rosenthal VD, Dendane T, Abidi K, Zeggwagh AA, and Abouqal, R (2009): Healthcare associated infections rates, length of stay, and bacterial resistance in an intensive care unit of Morocco: Findings of the International Nosocomial Infection Control Consortium (INICC). International Archives of Medicine; 2(29):1-7.

17. National Committee for Clinical Laboratory Standards (2009): Methods for dilution antimicrobial susceptibility tests for bacteria that grow aerobically. Approved standard M100-S19.

18. Navarro-San Francisco CL, Del Toro MD, Cobo J, De Gea-García JH, Vañó-Galván S, Moreno-Ramos F, Rodríguez-Baño J and PañoPardo JR (2013): Knowledge and perceptions of junior and senior Spanish resident doctors about antibiotic use and resistance: results of a multicenter survey. Enferm infec microbial clin; 31(4):199-204.

19. Pascale C and Gurses AP (2008): Nursing Workload and Patient Safety-A Human Factors Engineering Perspective. Available at: http://www.ncbi.nlm.nih.gov/books/NBK2657/

20. Patarakul K, Tan-Khum A, Kanha S, Padungpean D, Jaichaiyapum O (2005): Crosssectional survey of hand-hygiene compliance and attitudes of health care workers and visitors in the intensive care units at King Chulalongkorn Memorial Hospital. Journal Medical Association of Thailand; 88:S287.

21. Paudyal P, Simkhada P and Bruce J (2008): Infection control knowledge, attitude, and practice among Nepalese health care workers. Am J Infect Control; 36(8):595-7.

22. Radhakrishna M, D'Souza M, Kotigadde S, Saralaya KV and Kotian MS (2013): Prevalence of Methicillin Resistant Staphylococcus aureus Carriage amongst Health Care Workers of Critical Care Units in Kasturba Medical College Hospital, Mangalore, India. J Clin Diagn Res: (JCDR); 7(12): 2697-2700. Available at: http:// doi.org/10.7860/JCDR/2013/5160.3735

23. Malone B (2005): Good practice in infection prevention and control. Guidance for nursing staff, Royal College of Nursing. 1-16.

24. Sadaka SM (2009): Evaluation of different methods for the rapid diagnosis of methicillinresistance in Staphylococcus aureus. African Journal of Microbiology Research; 3:49-55.

25. Seibert D, Speroni K, Mi Oh K, DeVoe M and Jacobsen K (2014): Knowledge, perceptions, and practices of methicillin-resistant Staphylococcus aureus transmission prevention among health care workers in acute-care settings. AJIC; 42(3): 254-259.

26. Shibabaw A, Abebe T and Mihret A (2013): Nasal carriage rate of methicillin resistant Staphylococcus aureus among Dessie Referral Hospital Health Care Workers; Dessie, Northeast Ethiopia. Antimicrob Resist Infect Control; 2: 25. Available at: http://www.ncbi. nlm.nih.gov/pmc/articles/PMC3851550/.

27. Siegel J, Rhinehart E, Jackson M and Chiarello L (2007): Management of multidrug-resistant organisms in health care settings, 2006. AJIC; 35 (10 Suppl 2): S165-193.

28. Silva AM, Carvalho MJ, Canini SR, Cruz ED, Simões CL and Gir E (2010): Methicillin resistant staphylococcus aureus: knowledge and factors related to the nursing team's adherence to preventive measure. Revista Latino-Americana de Enfermagem; 18(3): 345-51. Available at: http://www.scielo.br/scielo.php?script=sci_ arttext\&pid=S0 104-11692010000300008\&lng $=$ en\&tlng $=$ en

29. Soliman GS, Abu-Youssef RM, Saleib BF, El-Moughazi AM and Zaki A (2013): Awareness of World Health Organization methicillin-resistant Staphylococcus aureus guidelines at Alexandria University hospitals. 
Eastern Mediterranean Health Journal; 19 (7).

30. Spellberg B, Gilbert DN (2014): The future of antibiotics and resistance: a tribute to a career of leadership by John Bartlett. Clin Infect Dis; 59 (2):S71-S75.

31. Stein AD, Makarawo TP and Ahmad MF (2003): A survey of doctors> and nurses> knowledge, attitudes and compliance with infection control guidelines in Birmingham teaching hospitals. $\mathbf{J}$ Hosp Infect; 54(1):68-73.
32. Yamakawa K, Tasaki O,Fukuyama M, Kitayama J, Matsuda H, Nakamori Y, et al. (2011): Assessment of risk factors related to healthcareassociated methicillin-resistant Staphylococcus aureus infection at patient admission to an intensive care unit in Japan. BMC (Bio Med Central) Infectious Diseases; 11:303. Available at: http://www.biomedcentral.com/14712334/11/303. 